\title{
Economic assessment of the effects of pollution of land resources
}

\author{
Raisa Damineva ${ }^{*}$, Nicolai Shulaev ${ }^{1}$, Valeria Pryanichnikova ${ }^{1}$, RamilKadyrov $^{1}$ and Nicolai Bykovsky ${ }^{1}$ \\ ${ }^{1}$ Federal State Budgetary Educational Institution of Higher Education, Ufa State Petroleum Technological University, Pr. Oktyabrya, 2, \\ Sterlitamak, Bashkortostan, 453118,Russian Federation
}

\begin{abstract}
The work highlights the need to use an interdisciplinary approach in the field of economics and industrial environmental management. The paper presents the current theoretical approaches to the economic assessment of damage from environmental pollution. The shortcomings of the existing methodological recommendations are noted, which consist in combining the assessment of economic damage at the micromacroeconomic levels of management, without taking into account the influence of the time factor. The need for sociological research to take into account the environmental, social and economic consequences of environmental pollution is also not considered. In this work, the basic model of economic assessment of land resources polluted by production and consumption waste is offered. The use of this model will allow leveling the shortcomings inherent in the existing methodological recommendations for assessing the economic damage from environmental pollution
\end{abstract}

\section{Introduction}

One of the directions of the interdisciplinary approach to the study of humanities and natural sciences is the consideration of issues of the relationship between the economy and nature conservation.

As known, industrial environmental management is a combination of all forms of use of natural resource potential and measures for its conservation [1]. Economics of environmental management is one of the branches of economic science which defines the management of production and economic activities of society, depending on the laws of nature development. This implies that the laws of natural transformations must be primary, and the laws of economic activity secondary.

The purpose of this study is to develop a scientific approach to the economic assessment of dynamic damage from environmental pollution. In our opinion, the use of dynamic approach to assessing economic damage is especially necessary when placing production and consumption waste on a land plot as well as when organizing waste processing facilities.

In the scientific literature and official methodological recommendations there are no proposals for integrating the results of sociological research into the economic evaluation of solutions to environmental problems associated with disposal of industrial and household waste.

Thus, we believe that the use of the interdisciplinary approach in the development of guidelines for economic assessment of the effects of pollution of land resources is relevant.

\section{Materials and methods}

As far as is known, a polluted environment has a negative impact on recipients, which causes the manifestation of environmental, social, economic consequences of pollution.

Ecological impacts of environmental pollution are caused by such level of change in the quantitative and qualitative composition of the air and water basins as well as of the soil, when the possibilities of the protective mechanism of natural forces are exceeded. The ecological consequences of environmental pollution are expressed in violation of the equilibrium in nature in relationships within and between individual systems.

The social consequences of environmental pollution are caused by changes in the conditions of human life and are determined by the degree of negative impact of pollutants on public health. This effect is manifested in increased level of morbidity, in decrease in life expectancy and the period of vigorous human activity.

Economic consequences are additional costs in the areas of material production, unproductive sphere and personal consumption due to the negative impact of polluted environments. Additional costs are due to the following reasons:

a) acceleration of physical deterioration of fixed assets in industry, transport, communication, housing and communal services;

b) loss of raw materials and products, together with waste gases and wastewater which leads to increase in the cost of wastewater treatment plants, the lack of part of the marketable products, environmental pollution;

c) decrease in the productivity of agriculture, fisheries and forestry;

d) insufficient receipt by the society of a part of net income due to increase of morbidity of population and increase in staff turnover;

\footnotetext{
*Corresponding author: daminevarm@mail.ru
} 
e) loss of the recreational value of the air and water basins, which causes the transfer of holiday homes, resorts and sanatoriums to other places.

The negative impact of the polluted environment causes the following types of costs [1].

The first group includes costs aimed at preventing the negative impact of the environment on recipients (if such preventing is technically possible).

The second group includes the costs caused by the negative impact of the polluted environment on recipients. The costs of the second type occur in the following cases:

a) if subsequent preventing of negative impact is impossible;

b) if the cost of complete preventing of negative impact is greater or equal to the sum of the costs of both types in the private prevention of negative effects on recipients.

The amount of expenses of the two types is called the economic damage caused to the national economy by the polluted environment.

In the economic literature there are two approaches to determine the economic damage from environmental pollution, in particular from the disposal of production and consumption waste. The first approach is based on taking into account local damages caused to individual areas of the national economy.

Comprehensive economic damage should consist of local damages for individual units of the national economy. When allocating local damages the important point is to establish their number.

On the one hand, the amount of local damages is limited by the compatibility of individual particular techniques. On the other hand, it can grow endlessly. A large number of local damages have positive and negative points.

The positive point is that it gives the impression of reliable detailed scientific analysis.

The negative points include the following. First, an increase in the number of factors affecting some process, and their full analysis does not indicate that all the main factors have been discovered. Secondly, the ratio between major local damage and secondary damages becomes incomparable.

It is believed that with the growth of local damages up to 30, the possibility of building a methodology for determining the complex economic damage from environmental pollution is lost.

As a rule, [1] the following composition of local damage is considered: damage to agriculture and forestry; damage to industry; damage to health care; damage to public utilities.

The second approach to the assessment of complex economic damage involves the calculation of economic damage separately by types of natural environments (air, water, soil).

Economic damage from pollution of the water and air basins is defined as the product of the specific damage inflicted by a unit of the reduced mass of pollutant, the reduced mass of emissions / discharges of harmful substances and coefficient that takes into account the ecological situation and ecological significance of the territory.

The economic damage from the deterioration and destruction of soils and lands under the influence of anthropogenic (man-made) loads is expressed in the following: degradation of soils and lands; land pollution with chemicals; land pollution by unauthorized landfills, other unauthorized and unregulated waste disposal; increasing the area allocated for waste disposal sites.

Based on the methodological recommendations for assessing damage from accidents at hazardous production facilities, it is recommended to determine the amount of environmental damage on the basis of calculating the charge for emissions / discharges of harmful substances.

\section{Results}

We propose not to combine the methodology for determining fees for disposal of production and consumption waste with the methodology for assessing environmental damage to the environment for the reasons that follow below.

First, the magnitude of the damage reflects macroeconomic losses, since it is determined throughout the distribution area of pollution.

Second, the economic damage reflects the results of changes in the degree of negative impact on the recipients of background of pollution that has developed in the area. The prevailing background of pollution arises from the activity of all pollution sources located in the area.

Thus, the economic damage is the cumulative result of all production and economic activities carried out in the study area and therefore cannot be compared with the amount of payment for emissions / discharges of harmful substances.

Another drawback of the existing methods of assessing the economic damage from environmental pollution is their static assessment, i.e. there is no consideration of the influence of time factor. We believe that the latter must be taken into account due to the following reasons:

1) a negative impact on recipients has not only one-time harmful effects of pollutants but also effects over a long stretch of time;

2) the value of cost indicators changes over time due to inflation processes.

The methodological recommendations do not take into account the results of sociological research in the economic assessment of the effects of environmental pollution and environmental performance.

To assess the dynamics of environmental pollution, we propose to apply the methods of mathematical statistics (time series analysis, correlation and regression). This will allow identifying the strength of relationship, time dependence of the studied factors of environmental pollution.

To take into account the social consequences of pollution of land resources, we propose to conduct sociological studies, the results of which will reveal how the population of the region perceives the degree of the impact of environmental pollution on its health. 
We propose the following principal model of the economic assessment of land resources polluted by production and consumption waste.

$$
y_{3}=\sum_{t=0}^{T} \frac{A_{C t} \cdot P+C_{\Pi t} \cdot K_{t}}{(1+e)^{t}}
$$

where $\mathrm{y}_{3}$ - the damage to land resources as a result of their pollution by industrial and household waste;

$\mathrm{T}$ - The final year of the period under review.

$\mathrm{A}_{\mathrm{Ct}}$ - the alternative value of the land in the $\mathrm{t}$-th year of the period under consideration;

$\mathrm{P}$-the probability of the considered alternative method of using this land plot;

$\mathrm{C}_{\Pi \mathrm{t}}$ - the average share of social consequences of pollution of land resources in the $t$-th year of the period under consideration, determined by the results of sociological research;

$K_{t}$ - the amount of investment associated with the production and economic activities of enterprises in the region;

$\mathrm{t}$ - the calculated year in the period under review;

$\mathrm{e}$ - the rate of discount.

To carry out a rapid economic assessment of contaminated land resources, you can use static methods for assessing damage. To do this, we recommend determining the damage to agriculture, using the concept of alternative cost. When calculating it, such elements as damage from the withdrawal of land from agricultural use, damage from shortage of crop products and damage from shortage of animal products are taken into account.

We explain the use of the alternative cost concept for the economic assessment of damage to land resources as a possible income for agricultural organizations by the following points.

Firstly, according to the data of Table 1 [3], the largest share $(22.4 \%)$ of the used land resources providing income belongs to agricultural organizations.

Table 1. Distribution of land fund by categories in the Russian Federation in 2018

\begin{tabular}{|l|c|}
\hline \multicolumn{1}{|c|}{ Category of land } & $\begin{array}{l}\text { The } \\
\text { territory } \\
\text { of land in } \\
\% \text { of the } \\
\text { total }\end{array}$ \\
\hline 1 Agricultural lands & 22,4 \\
\hline 2 Settlement lands & 1,2 \\
\hline $\begin{array}{l}\text { 3 Lands of industry, energy, } \\
\text { transport, communication, } \\
\text { broadcasting, television, and } \\
\text { other special purposes }\end{array}$ & 1,0 \\
\hline $\begin{array}{l}\text { 4 Lands of especially protected } \\
\text { territories and objects }\end{array}$ & 2,8 \\
\hline 5 Forest lands & 65,8 \\
\hline 6 Water resource lands & 1,6 \\
\hline 7 Reserve lands & 5,2 \\
\hline
\end{tabular}

Secondly, the economic assessment of land shows the use of land as the main means of production in agriculture and forestry [1]. The economic assessment of land involves the determination of the relative value of land as a means of production in agriculture due to natural, economic conditions.

There are the following main indicators of the economic assessment of land: crop yields; land productivity by types of land (the cost of gross crop production in rubles per 1 hectare); cost recovery (the ratio of the cost of products in cadastral prices to expenses); differential income (the cost of the additional surplus product on relatively better lands).

As follows from Table 1, the largest share of the territory $(65.8 \%)$ belongs to the forest lands. When assessing the damage caused to land resources that are part of the forest fund, we recommend applying the cost based concept. In this case, it is necessary to take into account the loss of market value of wood due to its drying out as well as the cost of cleaning and renewing the forest land.

For the economic valuation of forest resources, the concept of total economic value can be applied. According to it, the following indicators are evaluated: the cost of use and the cost of non-use. Cost of use includes direct cost, indirect cost and possible cost of use.

The indicator of direct costs of use is most amenable to economic evaluation. It takes into account the cost of harvested timber, medicinal plants, by-products (mushrooms, berries, and nuts), and income from tourism, hunting and fishing.

More complicated is the method of determining the indicator of indirect cost of use. In some studies, the indirect cost of forest use is defined as the effect of carbon dioxide sequestration (greenhouse effect reduction) and the effect of water-regulating functions performed by forest resources (flood abatement).

Even more difficult for calculation is the indicator of probable cost. It is associated with the conservation of a biological resource for probable future use. In this case, the probable cost is the adjusted amount of direct and indirect cost of use.

The non-use cost is based on the existence cost, which is an attempt to economically evaluate ethical and aesthetic aspects. They represent the duty of man to preserve nature to future generations. In assessing this value, simplified economic approaches are used, primarily related to the theory of "willingness to pay", i.e. the residents of the area with certain environmental value are asked about their willingness to pay for the preservation of this resource.

Rapid assessment was conducted by the authors when reviewing the results of studies on the electrochemical cleaning of oil-contaminated soils. These studies are carried out in the branch of FGBOU VO UGNTU in Sterlitamak.

To assess the damage caused to agriculture, we used statistical information on the activities of agricultural organizations in the Russian Federation [3]. At the same time, the damage from the shortage of crop production was calculated from such a grain crop as rye. Assessment of damage from the shortage of livestock products was carried out on livestock and poultry number. The following results were obtained.

The one-time cost of electrochemical cleaning of oilpolluted land is $88 \%$ less than the damage caused by the 
withdrawal of land from agricultural use, 92\% less than damage from a shortage of crop products, $71 \%$ less damage from a shortage of livestock products.

\section{Discussion}

The following points are being discussed in the paper.

First, when analyzing the dynamics and degree of environmental pollution, it is necessary to use methods of mathematical statistics, which will allow us to determine the time dependence of the identified factors of environmental pollution.

Second, along with statistical analysis of the social consequences of pollution of nature, we suggest conducting sociological research in order to identify the degree of public perception of waste formation and methods of utilization of industrial and household waste.

Third, in order to take into account the duration of impact of harmful effects of pollutants and the change in cost indicators over time, it is necessary to evaluate the influence of the time factor when calculating the economic damage from environmental pollution.

\section{Conclusion}

As a result of application of the proposed guidelines we get the following.

First, mathematical dependencies (patterns) of the environmental, social and economic consequences of environmental pollution will be revealed at the disposal of industrial and household waste.

Second, an ecological, technological and economic evaluation of the methods of reclamation of production and consumption wastes will be carried out.

Third, along with an economic assessment the results of sociological research will make it possible to identify the most effective methods of reclamation of industrial and household waste.

Thus, applying an interdisciplinary approach and taking into account the influence of the time factor as well as the results of sociological research it is possible to carry out in rather full volume an economic assessment of the results of environmental pollution at disposal and reclamation of industrial and household waste.

\section{Acknowledgment}

The reported study was funded by RFBR (Russian Foundation for Basic Research) according to research project No 18-29-24041

\section{References}

1. R.M. Damineva Economics of industrial environmental management: monograph (Ufa: Oil and Gas Business Publishing House) 80 (2016)

2. R.M. Damineva Methodical bases for assessing the effectiveness of environmental activities at chemical industry enterprises Bashkirian Chemical Journal 3, 93-96(2006)

3. Retrieved from: http://www.gks.ru/ - Goskomstat of the Russian Federation

4. L.I. Vanchukhina, T.B. Leybert, Y.R. Rudneva,A.R. Rogacheva, E.A. Khalikova,N.A. Galeeva Integrated assessment of the credit policy efficiency.10 $0^{\text {th }}$ International Scientific Conference "Business and Management 2018», May 3-4 Vilnius, Lithuania. Section: Financial Engineeringpp. 456-465 (2018)

5. L.I. Vanchukhina, T.B. Leybert, E.A. Khalikova, N.N. Luneva Modern approaches to operational planning in oil refinery using the PIMS software product // Quality-Access to Success, Vol. 19, S2, July 2 123-129 (2018)

6. L.I. Vanchukhina, T.B. Leybert, E.A. Khalikova Methodological approaches to evaluation and analysis of labor efficiency in the spheres of fuel and energy complex // Journal of Environmental Management and Tourism4 571-585 (2016)

7. L.I. Vanchukhina, T.B. Leybert, E.A. Khalikova, E. Shamonin The main directions of development of information production of Russia's tax system// Models of Modern Information Economy: Conceptual Contradictions and Practical Examples / Emerald Publishing Limited 265-274 (2018)

8. L.I. Vanchukhina, T.B. Leybert, Y.R. Rudneva, A.M. Rogacheva, E.A. Khalikova Closed-loop economy in the context of solving the global problems of modern times // Industry 4.0: Industrial Revolution of the 21st Century / Springer International Publishing AG, part of Springer Nature, V169. 31-53 (2019)

9. L.I. Vanchukhina, T.B. Leybert, E.A. Khalikova Features of the calculation of the cost of production in complex industries // Journal "SocarProceedings"3 66-72 (2016)

10. O. Belenkova, L.I. Vanchukhina, T.B. Leybert Human capital as socio-economic phenomenon of the innovation society: prerequisites of formation, essence and structure //SHS Web of Conferences 55, 01003 https://doi.org/10.1051/shsconf/20185501003 (2018)

11. Guidelines for evaluating the effectiveness of investment projects and their selection for financing. M. p 80 (1994)

12. Guidelines for determining prevented environmental damage, approved by the Chairman of the State Committee on Ecology of the Russian Federation Danilov-Danilyan V I p 17 (1999) 